
\title{
25 Research Soure \\ Platelet Derived Extracellular Vesicles Promote in Vitro Gingival Wound Healing.
}

\section{Miquel Antich-Rosselló}

Institut d'Investigació Sanitària de les Illes Balears

Marta Munar-Bestard

Institut d'Investigació Sanitària de les Illes Balears

Maria Antònia Forteza-Genestra

Institut d'Investigació Sanitària de les Illes Balears

Javier Calvo

Fundació Banc de Sang i Teixits de les Illes Balears

Antoni Gayà

Fundació Banc de Sang i Teixits de les Illes Balears

Marta Monjo

Universitat de les Illes Balears

Joana Maria Ramis ( $\square$ joana.ramis@uib.es )

Universitat de les Illes Balears https://orcid.org/0000-0001-9109-8362

\section{Research Article}

Keywords: Extracellular vesicles, platelet lysate, wound healing, hyaluronic acid, regeneration, gingival fibroblasts, gingival keratinocytes

Posted Date: September 21st, 2021

DOl: https://doi.org/10.21203/rs.3.rs-889480/v1

License: (c) (1) This work is licensed under a Creative Commons Attribution 4.0 International License.

Read Full License 


\section{Abstract}

Purpose: Gingival regeneration aims at restoring the architecture and functionality of oral damaged tissue. Different biomaterials or biological materials have been tested for tissue repair, such as platelet concentrates like platelet lysate $(\mathrm{PL})$. In this article, the use of extracellular vesicles (EVs) derived from PL and their combination with hyaluronic acid biomaterials $(\mathrm{HA})$ in wound healing was investigated.

Methods: EVs were isolated by size exclusion chromatography from PL. In addition, HA gels were formulated with PL or EVs. EVs or HA combined with EVs (HA-EVs) were tested in vitro for biocompatibility (LDH activity and metabolic activity) and by a wound healing assay and gene expression analysis.

Results: EVs and EVs-HA treatments were biocompatible and showed an increase in wound healing compared to control. Moreover, changes in gene expression related to extracellular matrix remodeling were observed in gingival keratinocytes and gingival fibroblasts after the treatment with EVs.

Conclusion: EVs can be combined with HA biomaterials, showing good biocompatibility and preserving their activity and functionality. Therefore, platelet derived EVs emerge as promising candidates for oral regeneration with the possibility to combine them with biomaterials in order to enhance their application in clinical use.

\section{Introduction}

Wound healing is a physiological process which aims at restoring the architecture and functionality of damaged tissue. The wound repair includes different phases that involve a complex cellular cascade: haemostasis, inflammation, proliferation and remodelling. ${ }^{1,2}$ The regeneration process is particularly important in gingival tissue. Epithelial wound healing is essential to assure tooth and periodontal tissue protection against trauma or infection, especially after dental intervention., 3

Gingival epithelial regeneration involves different cell types such as gingival fibroblasts and gingival keratinocytes. On the one hand, gingival fibroblasts are the major constituents of periodontal connective tissue. They maintain gingival tissue integrity by producing and organizing different extracellular matrix components such as collagen and proteoglycans. ${ }^{4}$ On the other hand, gingival keratinocytes form the outer layer of gingival tissue and create a protective barrier against external agents. ${ }^{5}$ In wound healing processes, gingival keratinocytes rapidly move to the injured area in order to cover the exposed connective tissue. ${ }^{4}$

Current regenerative approaches pursue a rapid wound healing response and tissue regeneration. ${ }^{2}$ Among the different strategies under research, the use of platelet concentrates, such as Platelet Rich Plasma (PRP) or Platelet Lysate (PL), has emerged due to platelet major role during wound healing. ${ }^{2}$ Research has shown that platelet concentrates can ease the regeneration of dental or periodontal 
tissues. ${ }^{6}$ Moreover, some studies show that platelets induce a wound healing response in fibroblasts and keratinocytes. ${ }^{7-9}$ Although the wound healing response induced by platelets have traditionally been associated to the direct effects of secreted biomolecules such as growth factors, recently it has been suggested that Extracellular Vesicles (EVs) could also be involved in the wound healing response. ${ }^{10,11}$

EVs are membranous particles, naturally released by cells, which play a key role in cell communication. ${ }^{12}$ They present a wide range of sizes, which extend from $30 \mathrm{~nm}$ up to $1000 \mathrm{~nm}$. EVs have been classified according to their origin. Thus, exosomes derive from the endosomal system, while microvesicles are generated by plasmatic membrane budding. ${ }^{13,14} \mathrm{EVs}$ are enriched in protein, lipids and nucleic acids (DNA, mRNA, miRNA, tRNA), which allows the communication with the receptor cell. ${ }^{15}$ Even more, the lipid bilayer of EVs protects the biomolecules they contain, preventing their degradation once released to the extracellular space. ${ }^{12}$ Their specific cargo depends on the cellular origin and conditions, being immune cells, mesenchymal stem cells, body fluids and dental related cells the most studied for oral regenerative medicine. ${ }^{11}$ However, only few studies have explored the role of platelet-derived EVs on oral wound healing, although EVs have already been suggested as major effectors of platelet concentrate activity. ${ }^{16}$

Moreover, the combination of biomaterials with EVs may improve its tissue regeneration capability. ${ }^{17}$ Among the different biomaterials that exist, hyaluronic acid biomaterials have been widely studied in periodontal regeneration. ${ }^{18,19}$ Hyaluronic acid is a component of the extracellular matrix able to modulate the regenerative process. ${ }^{20}$ Therefore, hyaluronic acid based biomaterials combined with platelet EVs could be good candidates for oral regenerative treatments.

Although platelet-derived EVs have been proposed as promoters of dermal fibroblast and keratinocyte migration and wound healing, ${ }^{21,22}$ lack of evidence remains in the use of platelet EVs in gingival tissue. Thus, here we have evaluated the gingival regenerative effects of $P L$ derived EVs on gingival keratinocytes and fibroblasts on its own as well as their combination with HA gels for periodontal applications.

\section{Material And Methods}

\section{Human PL preparation}

Fresh buffy coats were obtained from the IdISBa Biobank and their use for the current project was approved by its Ethics Committee (IB 1995/12 BIO). Platelet concentrates were obtained as previously described. ${ }^{23}$ Briefly, six buffy coats were pulled and a platelet concentrate was obtained after a centrifugation at $650 \times \mathrm{g}$ for $10 \mathrm{~min}$ and leucocyte filtration, then, at least three freeze/thaw cycles at -80 ${ }^{\circ} \mathrm{C}$ and $37^{\circ} \mathrm{C}$ were performed to lyse platelets. Cell debris were discarded by centrifugation at $5050 \times \mathrm{g}$ during 20 minutes at room temperature and supernatant was filtered by $40.0 \mu \mathrm{m}$ pore size membrane (Sartorius, Goettingen, Germany). PL was stored at $-20^{\circ} \mathrm{C}$ until use.

\section{EVs isolation}


PL was centrifuged at $1,500 \times \mathrm{g}$ for $15 \mathrm{~min}$ at $4^{\circ} \mathrm{C}$. The supernatant was filtered through $0.8 \mu \mathrm{m}$ porous membrane (Sartorius) for large cell debris elimination and then through $0.2 \mu \mathrm{m}$ porous membrane (Sartorius). PL was centrifuged at $10,000 \times \mathrm{g}$ for 30 minutes at $4^{\circ} \mathrm{C}$. The supernatant $(5 \mathrm{ml})$ was loaded on a Sepharose CL-2B precast column (GE Healthcare, Pittsburg, PA, USA). AKTA purifier system coupled with a collector Frac 950 (GE Healthcare) was used to set a flow rate at $0.5 \mathrm{ml} / \mathrm{min}$. EVs were eluted with PBS (Capricorn, Ebsdorfergrund, Germany) in $5 \mathrm{ml}$ fractions, which were collected and characterized.

\section{Transmission Electron Microscopy (TEM)}

Platelet-derived EV were fixed in $2 \%$ formaldehyde (Sigma-Aldrich) solution. Fixed EVs were set on copper Formvar-Carbon-coated grids (Ted Pella, Redding, California, USA) during 20 min and washed with PBS. Then, samples were incubated with $1 \%$ glutaraldehyde (Sigma-Aldrich) for 5 minutes and washed with deionized water. The samples were stained for 1 minute with $2 \%$ uranyl acetate (Electron Microscopy Sciences Hatfield, PA, USA) and washed with PBS. Images were taken using a TEM-H600 (Hitachi, Tokyo, Japan) at $50 \mathrm{kV}$

\section{Protein quantification}

Total protein amount of PL and EVs samples was quantified with BCA Protein Assay kit (Thermo Fisher, Waltham, MA, USA) following the manufacturer's instructions. Absorbance was read at $\lambda=562 \mathrm{~nm}$ (BioTek Instruments, Winooski, VT, USA).

\section{Western Blot}

$\mathrm{PL}$ and EVs samples were prepared with non-reducing Laemli loading buffer and denatured at $70^{\circ} \mathrm{C}$. Samples were loaded in a $12 \%$ gradient SDS-PAGE gel and proteins were separated by electrophoresis. The transfer was performed in humid conditions onto nitrocellulose membrane (GE Healthcare, Pittsburgh, PA, USA). A Ponceau S (Sigma-Aldrich) solution at $0.2 \% \mathrm{v} / \mathrm{v}$ was used for total protein visualization.

After several washes, membranes were blocked and incubated with anti-human CD9 (Thermo Fisher) and anti-human CD63 (Abcam, Cambridge, UK) antibodies. Secondary antibody incubation was performed with HRP-coupled anti-mouse IgG (Thermo Fisher). Chemiluminescence was induced with Clarity Western ECL Substrate (Bio-Rad, Hercules, CA, USA) and visualized after exposure on autoradiographic films (GE Healthcare).

\section{Nanoparticle Tracking Analysis (NTA)}

Size distribution and particle concentration were analysed with Nanosight NS300 (Malvern Instruments, Malvern, UK). Samples were diluted (1:100) to a final volume of $1 \mathrm{ml}$ and recorded with a laser at $\lambda=532$ $\mathrm{nm}$ and an sCMOS camera. Data was analysed with NTA 3.2 Dev Build 3.2.16 Software. Once the number of particles was set, purity ratio was calculated by the formula described by Webber et al. (Eq. 1): ${ }^{24}$ 
Purity $($ particles $/ \mu \mathrm{g})=\frac{\text { Particle concentration }}{\text { Protein concentration }}$

(Eq. 1)

\section{Hydrogel preparations}

Hydrogels based on hyaluronic acid (Bioibérica, F002103, Mw 800-1,200 kDa, Spain) were prepared at 2 $\%(\mathrm{w} / \mathrm{v})$ by incubating overnight at $25^{\circ} \mathrm{C}$. Thus, three different hydrogels were obtained: (1) Hyaluronic acid hydrogel (HA) for which PBS was used; (2) PL containing hyaluronic acid hydrogel (HA-PL) for which PBS containing PLwas used to obtain a final protein concentration of $0.167 \mu \mathrm{g} / \mu \mathrm{l}$; (3) EVs containing hyaluronic acid hydrogel (HA-EVs), for which PBS containing EVs was used to obtain a final protein concentration of $0.167 \mu \mathrm{g} / \mu \mathrm{l}$.

\section{Equilibrium swelling ratio determination}

The equilibrium swelling ratio (ESR) of the hydrogels was determined for HA, HA-PL and HA-EVs. $1 \mathrm{ml}$ of each gel was incubated in PBS at $37^{\circ} \mathrm{C}$ for $3 \mathrm{~h}$ or $24 \mathrm{~h}$. Then each gel was centrifuged at $16,000 \times \mathrm{g}$ for 15 min and the wet pellets were weighted $\left(\mathrm{W}_{\mathrm{w}}\right)$; supernatants were stored at $-80^{\circ} \mathrm{C}$ for release studies. Then, hydrogels pellets were frozen at $-80^{\circ} \mathrm{C}$ and lyophilized during $72 \mathrm{~h}$. Dried products were weighted again $\left(W_{d}\right)$. The experiment was performed in triplicate. ESR values were determined using the following equation (Eq. 2):

$E S R=\frac{W_{w}-W_{d}}{W_{d}}$

(Eq. 2)

\section{EVs Release}

The supernatants obtained after the 16,000 $\times \mathrm{g}$ centrifugation step of the ESR determination were stored at $-80^{\circ} \mathrm{C}$. HA-EVs supernatants were analyzed by NTA to determine the number of particles released after $3 \mathrm{~h}$ or $24 \mathrm{~h}$ incubation during the swelling experiments.

\section{Cell culture}

Immortalized Human Gingival Keratinocytes (ihGK, Applied Biological Materials Inc., Richmond, BC, Canada) and Immortalized Human Gingival Fibroblasts-hTERT (ihGF, Applied Biological Materials Inc) were grown at $37^{\circ} \mathrm{C}$ and $5 \% \mathrm{CO} 2$ atmosphere. The culture medium was renewed twice per week.

Keratinocytes were cultured on tissue culture flasks for sensitive adherent cells (Sarstedt, Germany) using Dulbecco's modified Eagle's medium (DMEM) without magnesium and calcium (Gibco, Grand Island, NY, US) and Ham's F12 (Biowest, Nuaille, France) in a 2:3 proportion, supplemented with $0.01 \mathrm{mg} / \mathrm{ml}$ insulin (Sigma-Aldrich), $0.4 \mathrm{ng} / \mathrm{ml}$ hydrocortisone (Sigma-Aldrich), $6.7 \mathrm{ng} / \mathrm{ml}$ selenium (Sigma-Aldrich), 0.01 $\mu \mathrm{g} / \mathrm{ml}$ human epithelial growth factor (ThermoFisher Scientific, Waltham MA, USA), 1M HEPES-buffer 
(Biowest), $5.5 \mu \mathrm{g} / \mathrm{ml}$ transferrin (Sigma-Aldrich), $0.1 \mathrm{nM}$ cholera toxin (Sigma-Aldrich), $2 \mathrm{mM}$ L-glutamine (Sigma-Aldrich), $5 \%$ (v/v) fetal bovine serum embryonic stem cells tested (FBS, Biowest) and $100 \mu \mathrm{g} / \mathrm{ml}$ penicillin and $100 \mu \mathrm{g} / \mathrm{ml}$ streptomycin (Biowest).

Fibroblasts were cultured in DMEM low glucose (Biowest) and Ham's F12 (Biowest) in a 2:1 proportion, supplemented with $10 \%$ (v/v) FBS (Biowest) and $100 \mu \mathrm{g} / \mathrm{ml}$ penicillin, and $100 \mu \mathrm{g} / \mathrm{ml}$ streptomycin (Biowest).

\section{Wound healing assay}

Cells were seeded in 48-well plates at a density of 20,000 cells/well. When confluence was reached, cells were washed twice with PBS and the medium was replaced by medium without supplements and containing $1 \%(\mathrm{v} / \mathrm{v})$ EV's depleted FBS. EV's depletion was performed by ultracentrifugation at $120000 \times$ $\mathrm{g}$ for $18 \mathrm{~h}$ at $4{ }^{\circ} \mathrm{C}$. Three independent experiments were performed having triplicates in each $(\mathrm{n}=9)$. All experiments were conducted in parallel and under the same conditions. Thus, PL and EVs in vitro studies, either alone or combined with HA, present the same control group to compare the different effects.

Wound was performed by scraping the cell monolayer with a $100 \mu \mathrm{l}$ sterile pipette tip in a straight line to create a scratch, cell medium was renewed, and the treatments were applied according to the group. The different groups tested were Control (it had the medium renewed but no treatment), PL ( $5 \mu \mathrm{g}$ of PL per well), EVs $(5 \mu \mathrm{g}$ of EVs per well), HA (30 $\mu \mathrm{l}$ of HA gel per well), HA-PL $(30 \mu \mathrm{l}$ of HA-PL gel per well, which contains $5 \mu \mathrm{g}$ of $\mathrm{PL})$ and HA-EVs $(30 \mu \mathrm{l}$ of HA-EVs gel per well, which contains $5 \mu \mathrm{g}$ of EVs).

Images of the same areas were taken using a bright-field inverted microscope (Nikon Eclipse TS100) before treatment and 3 hours after healing in ihGK and $24 \mathrm{~h}$ after healing in ihGF. The images were analysed with ImajeJ software. The wound closure area (\%) was defined as the difference of the scratch area before $\left(A_{i}\right)$ and after the treatment $\left(A_{f}\right)$ and normalized by the initial scratch area (Eq. 3).

Wound closure area $(\%)=\frac{A_{i}-A_{f}}{A_{f}} \cdot 100$

(Eq. 3)

\section{Cell Cytotoxicity}

Cell media was collected after $3 \mathrm{~h}$ of treatment for ihGK and $24 \mathrm{~h}$ of treatment for ihGF. Lactate dehydrogenase (LDH) activity was measured with Cytotoxicity Detection kit (Roche Diagnostics, Manheim, Germany) following the manufacturer's instructions. For cytotoxicity calculation (Eq. 4), $0.1 \%$ Triton-X100 treated wells were used as high control, $100 \%$ cell death, while non-treated wells were used as low control, $0 \%$ cell death.

Citotoxicity $(\%)=\frac{\text { experimental value }- \text { low control }}{\text { high control }- \text { low control }} \cdot 100$ 
(Eq. 4)

\section{Metabolic activity}

Total metabolic activity was evaluated after $3 \mathrm{~h}$ of treatment for ihGK and $24 \mathrm{~h}$ of treatment for ihGF. Presto Blue reagent (Life Technologies, Carlsbad, CA) was used during $1 \mathrm{~h}$ of reagent incubation time following manufacturer's protocol. Non-treated cells were set as $100 \%$.

\section{Gene Expression by Real-Time RT-PCR}

RNA was isolated using RNAzol® RT (Molecular Research Center, Cincinnati, OH, USA). RNA concentration was quantified with NanoDrop spectrophotometer (NanoDrop Technologies, Wilmington, DE, USA) and normalized for reverse transcription to cDNA using High Capacity RNA-to-cDNA kit (Applied Biosystems, Foster City, CA, USA).

Real-time PCR was performed for three reference genes and different target genes ${ }^{25}$ (Table 1) using the Lightcycler 480 thermocycler (Roche Diagnostics) and SYBR green detection. Each reaction well contained Lightcycler 480 SYBR Green I Master (Roche Diagnostics), $0.5 \mu \mathrm{M}$ of each primer, the sense and the antisense, and $3 \mu \mathrm{l}$ of the cDNA dilution in a final volume of $10 \mu \mathrm{l}$. The amplification program started with 5 min pre-incubation step for cDNA template denaturation at $95^{\circ} \mathrm{C}$, followed by 45 cycles consisting of $10 \mathrm{~s}$ steps of denaturation at $95^{\circ} \mathrm{C}$, annealing at $60^{\circ} \mathrm{C}$ and an extension at $72{ }^{\circ} \mathrm{C}$. Fluorescence was measured at $72^{\circ} \mathrm{C}$ after each cycle. 
Table 1

Genes and their sense (S) and antisense (A) primer sequences used in the real-time RT-PCR.

\begin{tabular}{|c|c|c|c|}
\hline Gen & Primer sequence $\left(5^{\prime}-3^{\prime}\right)$ & $\begin{array}{l}\text { Product } \\
\text { size } \\
\text { (bp) }\end{array}$ & GenBank ID \\
\hline \multirow[t]{2}{*}{ Collagen I a1 (COL1A1) } & S: CCTGACGCACGGCCAAGAGG & \multirow[t]{2}{*}{122} & \multirow[t]{2}{*}{ NM_000088.3 } \\
\hline & A: GGCAGGGCTCGGGTTTCCAC & & \\
\hline \multirow[t]{2}{*}{ Decorin (DCN) } & S: ATCTCAGCTTTGAGGGCTCC & \multirow[t]{2}{*}{146} & \multirow[t]{2}{*}{ NM_001920.3 } \\
\hline & A: GCCTCTCTGTTGAAACGGTC & & \\
\hline \multirow{2}{*}{$\begin{array}{l}\text { Matrix metalloproteinase- } 1 \\
\text { (MMP-1) }\end{array}$} & S: TGTCAGGGGAGATCATCGGGAC & \multirow[t]{2}{*}{177} & \multirow[t]{2}{*}{ NM_002421.3 } \\
\hline & A: TGGCCGAGTTATGAGCTGCA & & \\
\hline \multirow{2}{*}{$\begin{array}{l}\text { Tissue inhibitor of } \\
\text { metalloproteinases } 1 \text { (TIMP- } \\
\text { 1) }\end{array}$} & S: TTCCGACCTCGTCATCAGGG & \multirow[t]{2}{*}{144} & \multirow[t]{2}{*}{ NM_003254.2 } \\
\hline & A: TAGACGAACCGGATGTCAGC & & \\
\hline \multirow{2}{*}{$\begin{array}{l}\text { a-Smooth muscle actin } 2 \\
\text { (ACTA2) }\end{array}$} & S: TAAGACGGGAATCCTGTGAAGC & \multirow[t]{2}{*}{184} & \multirow[t]{2}{*}{ NM_001141945.1 } \\
\hline & A: TGTCCCATTCCCACCATCAC & & \\
\hline \multirow{2}{*}{$\begin{array}{l}\text { Transforming growth factor- } \\
\beta 1 \text { (TGF-B) }\end{array}$} & S: TGTCACCGGAGTTGTGCGGC & \multirow[t]{2}{*}{131} & \multirow[t]{2}{*}{ NM_000660.4 } \\
\hline & A: GGCCGGTAGTGAACCCGTTG & & \\
\hline \multirow[t]{2}{*}{ Endothelin-1 (EDN) } & S: ACGGCGGGGAGAAACCCACT & \multirow[t]{2}{*}{147} & \multirow[t]{2}{*}{ NM_001955.4 } \\
\hline & A: ACGGAACAACGTGCTCGGGA & & \\
\hline \multirow[t]{2}{*}{ Fibronectin (FN1) } & $\begin{array}{l}\text { S: } \\
\text { CGGAGAGACAGGAGGAAATAGCCCT }\end{array}$ & \multirow[t]{2}{*}{150} & \multirow[t]{2}{*}{ NM_001365522.2 } \\
\hline & A: TTGCTGCTTGCGGGGCTGTC & & \\
\hline \multirow[t]{2}{*}{ Vimentin (VIM) } & S: GGCCGCCTGCAGGATGAGATTC & \multirow[t]{2}{*}{153} & \multirow[t]{2}{*}{ NM_003380.5 } \\
\hline & A: CAGAGAAATCCTGCTCTCCTCGC & & \\
\hline \multirow{2}{*}{$\begin{array}{l}\text { Glyceraldehyde-3-phosphate } \\
\text { dehydrogenase (GAPDH) }\end{array}$} & S: TGCACCACCAACTGCTTAGC & \multirow[t]{2}{*}{87} & \multirow[t]{2}{*}{ NM_002046.3 } \\
\hline & A: AAGGGACTTCCTGTAACAA & & \\
\hline \multirow[t]{2}{*}{ Beta-Actin (ACTBL2) } & S: CTGGAACGGTGAAGGTGACA & \multirow[t]{2}{*}{140} & \multirow[t]{2}{*}{ NM_001101.3 } \\
\hline & A: AAGGGACTTCCTGTAACAA & & \\
\hline \multirow{2}{*}{$\begin{array}{l}\text { 18S ribosomal RNA ( } 18 \mathrm{~S} \\
\text { rRNA) }\end{array}$} & S: GTAACCCGTTGAACCCCATT & \multirow[t]{2}{*}{151} & NR_146156.1 \\
\hline & A: CCATCCAATCGGTAGTAGCG & & \\
\hline
\end{tabular}

Notes: Abbreviations: 18S rRNA, 18S ribosomal RNA; A, Sequence of antisense; ACTA2, a-Smooth muscle actin 2; ACTBL2, Beta-actin; bp, Base pairs; COL1A1, Collagen I a1; DCN, Decorin; END, Endothelin-1; ESR, 
Equilibrium swelling ratio; EVs, Extracellular vesicles; FBS, Fetal bovin serum embryonic stem cells tested; FN1, Fibronectin; GAPDH, Glyceraldehyde-3-phosphate dehydrogenase; HA, Hyaluronic acid; HA-EVs, Hyaluronic acid gel containing EVs; HA-PL, Hyaluronic acid gel containing PL; ihGF, Immortalized Human Gingival Fibroblasts-hTERT; ihGK, Immortalized Human Gingival Keratinocytes; LDH, Lactate dehydrogenase; MMP-1, Matrix metalloproteinase-1; NTA, Nanoparticle Tracking Analysis; PBS, Dulbecco's Phosphate Buffered Saline; PL, Platelet Lysate; PRP, Platelet Rich Plasma; S, Sequence of sense; TEM, Transmission electron microscopy; TGF-B1, Transforming growth factor- $\beta 1$; TIMP- 1 , Tissue inhibitor of metalloproteinase-1; VIM, Vimentin.

For relative quantification, standard curves were constructed for all genes. The Second Derivative Maximum Method provided by the LightCycler480® analysis software version 1.5 (Roche Diagnostics) was used to calculate the amount of each gene from the crossing point data. Reference genes were used to normalize the target genes expression levels and changes were compared to Control group, which was set to $100 \%$.

\section{Statistical analysis}

For statistical analysis, SPSS program version 25.0 (SPSS Inc., Chicago, IL, USA) and GraphPad Prism (version 7, La Jolla, CA, USA) were used. All data are presented as mean values \pm SEM. Normality was determined using Shapiro-Wilk test. For parametric distributed groups, one-way ANOVA was performed to identify differences between the groups while Levene's test for variance homogeneity. When homogeneities were comparable DMS post-hoc was used; if they were not, Games-Howell test was used. Differences between non-parametric groups were checked with Kruskal-Wallis test. Results were considered statistically significant at $p<0.05$.

\section{Results}

\section{Platelet-derived EVs characterization}

EV isolation and characterization were performed according to ISEV recommendations (Fig. 1). ${ }^{26}$ Widefield TEM images were used to confirm the presence of vesicles bodies (Fig. 1A). Then, EVs were analysed by NTA showing a heterogeneous population with a median size \pm standard error of $106.0 \pm 2.5$ $\mathrm{nm}$ (Fig. 1B). Moreover, through the particle content (3.8-1011 particles $/ \mathrm{ml})$ and the protein concentration $(167 \mu \mathrm{g} / \mathrm{ml})$ the purity ratio of $2.3 \cdot 10^{9}$ particles $/ \mu \mathrm{g}$ was obtained. ${ }^{24}$ Specific EV markers (CD9 and CD63) were confirmed by western blot (Fig. 1C).

\section{PL and EVs effect on ihGK and ihGF}

To evaluate the effects of PL and the PL-derived EVs, an in vitro functional study was performed using ihGK and ihGF (Fig. 2). The wound closure area, metabolic activity and LDH activity were determined $3 \mathrm{~h}$ after the wound for inGK (Fig. 2A, 2B, 2C, 2D) and $24 \mathrm{~h}$ after the wound for ihGF (Fig. 2E, 2F, 2G, 2H). In both cell lines, EVs presented a statistically significant increase of wound closure compared to the 
Control (Fig. 2A, 2B, 2E, 2F). Moreover, PL and EVs treated fibroblasts showed higher metabolic activity than the Control 24h after wound and treatment (Fig. 2G). No cytotoxicity was found for any of the groups (Fig. 2D and 2H).

Additionally, mRNA expression levels for different marker genes were evaluated for both cell lines (Fig. 3). No differences were observed in FN1 and VIM expression for inGK (Fig. 3A). However, ihGF treated with EVs presented increased levels for all the genes but for $D C N$, reaching significance for COL 1A1, MMP1 compared to control and PL and TGF $\beta$ compared to control (Fig. 3B, 3C).

\section{HA gels characterization}

The equilibrium swelling ratio was determined for the different HA gels (Fig. 4A). As expected, higher ESR were observed for for all gel formulations at $24 \mathrm{~h}$ than at $3 \mathrm{~h}$. However, HA-PL and HA-EVs presented lower ratios than HA in both time points, reaching statistical significance the ESR for HA EVs at $3 \mathrm{~h}$ compared to control. Additionally, the EVs release over time for HA-EVs group was determined by NTA (Fig. 4B). HA-EVs presented a sustained release over the time period evaluated, with higher amount of particle released at $24 \mathrm{~h}$ than at $3 \mathrm{~h}$ (Fig. 4B).

\section{In vitro effect of the different HA gels.}

The different HA gels were evaluated in an in vitro functional study (Fig. 5). For ihGK, cell closure area was significantly higher for HA-PL and HA-EVs after $3 \mathrm{~h}$ of treatment compared to the Control (Fig. 5A, 5B). Moreover, an increase in metabolic activity was observed for both groups, HA-PL and HA-EVs (Fig. 5C). No cytotoxicity was induced by any of the treatment groups in inGK cells (Fig. 5D). In addition, inGF treated with HA-PL or HA-EVs also showed increased wound closure area compared to the control. Even more, HA-EVs treated cells presented a significantly more closed wound compared to the HA treated group (Fig. 5E, 5F). Higher metabolic activity in ihGF was observed for all treated groups compared to the Control one (Fig. 5G). Furthermore, any of the treatments induced any cytotoxicity as measured by LDH activity released to the cell culture media (Fig. $5 \mathrm{H}$ ).

Gene expression was determined for cells treated with the different HA formulated gels (Fig. 6). inGK treated with HA-EVs presented lower expression levels of VIM compared to the Control group and the HA treated group, while no differences were observed for FN1 expression levels (Fig. 6A). Furthermore, ihGF treated with HA-EVs showed higher expression levels of COL1A1 and MMP1 mRNA and lower levels of $D C N$ mRNA compared to all other groups. HA and HA-PL presented a lower level of COL $1 A 1$ and DCN expression compared to the Control, while HA-PL also showed higher MMP1 expression levels compared to the Control (Fig. 6B). As for the gene expression levels of $T G F \beta$, HA treated cells showed lower expression levels than the Control and the HA-EVs groups, while HA-PL showed lower TGF $\beta$ expression levels compared to the Control. Finally, HA-EVs showed decreased expression levels of ACTA than the Control and HA groups, while presented increased EDN levels compared to all the other groups (Fig. $6 \mathrm{C}$ ). 


\section{Discussion}

Gingival epithelial wound healing and regeneration is essential for tooth and periodontal tissue protection. In the last decade, platelet concentrates have increasingly been used for dental and periodontal tissue regeneration. ${ }^{2,6}$ Here, we propose the use of platelet derived Extracellular Vesicles for gingival regeneration, proving its in vitro regenerative effect on gingival keratinocytes and fibroblasts, both, on its own and combined with hyaluronic acid gels.

In this study, we demonstrate that PL-derived EVs increase wound closure both in gingival keratinocytes and fibroblasts. Previous studies had already proven the regenerative effect of platelets, but these effects were mainly attributed to the released proteins, like growth factors. ${ }^{7-9}$ Our results, show higher effects for the EVs groups, suggesting higher healing effects for EVs than for the secreted proteins. Therefore, platelet-derived EVs could be an effective substitute for platelet concentrates in regenerative medicine. A highlight of this work is the high purity of the used EVs, since a purification by size exclusion chromatography was performed and only the fractions rich on EVs and poor on protein content were used. Isolated EVs were characterized according to the ISEV recommendations, ${ }^{26}$ presenting an heterogeneous population of small EVs positive in CD9 and CD63.

Additionally, in this study, PL and the EVs have been combined with HA gels. The HA gels formulation enables a topical or intradermal application which would allow a future clinical use and industrial development for oral interventions. ${ }^{27} \mathrm{HA}$ is a highly porous and hydrophilic biomaterial which allows a proper interaction with the physiological environment. ${ }^{28}$ The ESR values obtained are relatively high, but they decrease when HA is combined with PL or EVs, probably due to their lipophilic nature. In vitro studies show that wound healing response was improved in both gingival cell types by HA treatment as expected from previous reports. ${ }^{27}$ What is more, this effect was enhanced by the combination of HA with PL or EVs, showing HA-EVs the better result in agreement with the effects observed for non-formulated EVs.

After a wound, a series of sequential responses are activated to reconstitute the damaged tissues. On one hand, diverse cell types must migrate, proliferate and differentiate; on the other hand, these cells must secrete and organize several molecules of the extracellular matrix, including collagens, fibronectin and proteoglycans. ${ }^{29}$ These process are governed by a complex array of signals and involve the regulation of the expression of numerous genes. ${ }^{30}$ For instance, fibronectin is a component of the extracellular matrix that induces wound healing and cell adhesion, migration and differentiation, ${ }^{31}$ while VIM is associated with the cytoskeleton reorganization and induce cell proliferation and migration during the regeneration process in keratinocytes. ${ }^{32}$ The expression of these two genes in ihGK 3 hours after wounding and treatment with PL or EVs, was evaluated finding no significant differences. However, HA combined treatments present a decreasing tendency in VIM and FN1 on ihGK, probably because hyaluronic acid is an extracellular matrix glycosaminoglycan involved in cell matrix formation, ${ }^{33}$ therefore neither VIM nor FN1 production are required when $\mathrm{HA}$ is supplied to the cells. Similar effects are observed towards COL $1 A 1$ and DCN expression in ihGF 24 hours after wounding and treatment. COL1A1 and DCN are 
components of the extracellular matrix, ${ }^{34}$ thus HA treated group presented a decrease in both, corroborating the direct functionality associated to the hyaluronic acid itself. In addition, the decrease of $D C N$ can be associated to a higher cellular proliferation as higher levels of $D C N$ expression are related to quiescence and growth inhibition. ${ }^{35}$

In addition, COL1A1 is a component of the extracellular matrix while MMP1 is an enzyme that degrade collagen proteins. ${ }^{36}$ When EVs were used as treatment for their own or combined with $\mathrm{HA}$, an increase on COL 1A1 and MMP1 mRNA levels was observed. The expression of both proteins simultaneously suggests a remodeling process of the extracellular matrix which promotes a scarless and not fibrotic repair. ${ }^{37}$ Moreover, EVs treated groups presented higher levels of TGF- $\beta 1$ or END. These are proteins that promote COL1A1 production and enhance cell proliferation. ${ }^{36}$ However, TGF- $\beta 1$ and EDN are also responsible for an increase in ACTA levels which can lead to myofibroblast differentiation. ${ }^{38}$ In our study, ACTA presents a non-significant increasing tendency in $\mathrm{PL}$ or EV treated cells, while it decreases for HA$\mathrm{PL}$ and HA-EVs groups. Therefore, HA-EV treatment would reduce the myofibrotic regeneration risk while maintaining the regenerative properties of EVs. As regards to the biocompatibility, HA combined treatments presented low levels of LDH activity, under the $30 \%$, which is set as the maximum accepted cytotoxicity value for medical devices according to ISO-10993:5, and improved levels of metabolic activity, indicating both the safety of the treatment.

Overall, EVs achieve improved regenerative effects compared to the direct use of PL. These effects may be caused due to different properties of EVs. On the one hand, despite having normalized the protein amount, EVs may contain other functional biomolecules such as nucleic acids or active lipids. ${ }^{39}$ On the other hand, EVs protect the cargo from degradation and enhance their delivery to the target cells. ${ }^{40}$ Therefore, PL seems to present an increment of wound closure, probably caused mainly by proteins, while EVs have higher effects thanks to the encapsulation of these proteins and other active biomolecules and an enhanced delivery. ${ }^{41,42}$ In fact, different miRNAs contained in EVs derived from different cell types have been suggested to modulate wound healing. ${ }^{43,44}$ Nevertheless, further research should be performed to confirm the presence of these biomolecules in platelet derived EVs and their mechanism of action.

\section{Conclusion}

In conclusion, platelet derived EVs present a good biocompatibility in vitro and a regenerative effect on both gingival keratinocytes and fibroblasts. Moreover, EVs induce changes on expression levels of genes associated with the remodeling process during wound healing. Finally, EVs can be combined with HA gels to produce more applicable treatments while preserving their regenerative effects.

\section{Declarations}

Ethics approval and consent to participate: Not applicable

Consent for publication: Not applicable

Page $12 / 23$ 
Availability of data and material: Data available on request due to restrictions. The data present in this study are available on request from the corresponding authors.

Funding: This research was funded by Instituto de Salud Carlos III, co-funded by the ESF European Social Fund and the ERDF European Regional Development Fund (contract to J.M.R; MS16/00124 and M.M.B; FI18/00104 and project PI17/01605) and the Direcció General d'Investigació, Conselleria d'Investigació, Govern Balear (contract to M.A.R.; FPI/2046/2017) and the Institut d'Investigació Sanitària de les Illes Balears (contract to M.A.F.G; ITS2018-002-TALENT PLUS JUNIOR PROGRAM, JUNIOR18/01).

Authors' contributions: M.A.R., M.M.B., M.M. and J.M.R. contributed to the conception and design. J.C. and A.G. provided hUC-MSCs and PL. M.A.F.G. and M.A.R. produced EVs samples. M.M.B and M.A.R. acquired and analysed data in the in vitro study. M.A.R., M.M.B, M.M. and J.M.R. contributed to interpretation of the results. M.A.R. wrote the main manuscript text and M.A.R., M.M.B, M.A.F.G., J.C., A.G., M.M. and J.M.R reviewed the manuscript.

Acknowledgments: The authors thank SCT-UIB for access to their facilities.

Competing Interests: Authors declare no conflict of interest

\section{References}

1. Smith, P.C., Cáceres, M., Martínez, C., Oyarzún, A., Martínez, J. Gingival wound healing: An essential response disturbed by aging? Journal of Dental Research. 94 (3), 395-402, doi: $10.1177 / 0022034514563750$ (2015).

2. Etulain, J. Platelets in wound healing and regenerative medicine. Platelets. 29 (6), 556-568, doi: 10.1080/09537104.2018.1430357 (2018).

3. Gibbs, S., Roffe, S., Meyer, M., Gasser, A. Biology of soft tissue repair: Gingival epithelium in wound healing and attachment to the tooth and abutment surface. European Cells and Materials. 38, 63-78, doi: 10.22203/eCM.v038a06 (2019).

4. L., H., V.J., U., H., L. Cell biology of gingival wound healing. Periodontology 2000. 24, 127-152 (2000).

5. Nikoloudaki, G., Creber, K., Hamilton, D.W. Wound healing and fibrosis: A contrasting role for periostin in skin and the oral mucosa. American Journal of Physiology - Cell Physiology. 318 (6), C1065C1077, doi: 10.1152/ajpcell.00035.2020 (2020).

6. Xu, J., Gou, L., Zhang, P., Li, H., Qiu, S. Platelet-rich plasma and regenerative dentistry. Australian Dental Journal. 65 (2), 131-142, doi: 10.1111/adj.12754 (2020).

7. Shin, M.K., Lee, J.W., Kim, Y. II, Kim, Y.O., Seok, H., Kim, N.I. The effects of platelet-rich clot releasate on the expression of MMP-1 and type I collagen in human adult dermal fibroblasts: PRP is a stronger MMP-1 stimulator. Molecular Biology Reports. 41 (1), 3-8, doi: 10.1007/s11033-013-2718-9 (2014). 
8. Anitua, E., Pino, A., Orive, G. Plasma rich in growth factors promotes dermal fibroblast proliferation, migration and biosynthetic activity. Journal of Wound Care. 25 (11), 680-687, doi: 10.12968/jowc.2016.25.11.680 (2016).

9. Anitua, E., Sanchez, M., Merayo-Lloves, J., de La Fuente, M., Muruzabal, F., Orive, G. Plasma rich in growth factors (PRGF-Endoret) stimulates proliferation and migration of primary keratocytes and conjunctival fibroblasts and inhibits and reverts TGF- $\beta 1$-induced myodifferentiation. Investigative Ophthalmology and Visual Science. 52 (9), 6066-6073, doi: 10.1167/iovs.11-7302 (2011).

10. Cabral, J., Ryan, A.E., Griffin, M.D., Ritter, T. Extracellular vesicles as modulators of wound healing. Advanced Drug Delivery Reviews. 129 (2018), 394-406, doi: 10.1016/j.addr.2018.01.018 (2018).

11. Lv, L., Sheng, C., Zhou, Y. Extracellular vesicles as a novel therapeutic tool for cell-free regenerative medicine in oral rehabilitation. Journal of Oral Rehabilitation. 47 (S1), 29-54, doi:

10.1111 /joor.12885 (2020).

12. Théry, C. Exosomes: secreted vesicles and intercellular communications. F1000 Biology Reports. 3 (July), 15, doi: 10.3410/B3-15 (2011).

13. Yáñez-Mó, M. et al. Biological properties of extracellular vesicles and their physiological functions. Journal of extracellular vesicles. 4, 27066, doi: 10.3402/jev.v4.27066 (2015).

14. Fais, S. et al. Evidence-Based Clinical Use of Nanoscale Extracellular Vesicles in Nanomedicine. ACS Nano. acsnano.5b08015, doi: 10.1021/acsnano.5b08015 (2016).

15. Penfornis, P., Vallabhaneni, K.C., Whitt, J., Pochampally, R. Extracellular vesicles as carriers of microRNA, proteins and lipids in tumor microenvironment. International Journal of Cancer. 138 (1), 14-21, doi: 10.1002/ijc.29417 (2016).

16. Torreggiani, E., Perut, F., Roncuzzi, L., Zini, N., Baglìo, S.R., Baldini, N. Exosomes: novel effectors of human platelet lysate activity. European cells \& materials. 28, 137-51; discussion 151, doi: 10.22203/ecm.v028a11 (2014).

17. Brennan, M., Layrolle, P., Mooney, D.J. Biomaterials Functionalized with MSC Secreted Extracellular Vesicles and Soluble Factors for Tissue Regeneration. Advanced Functional Materials. 30 (37), doi: 10.1002/adfm.201909125 (2020).

18. Fujioka-Kobayashi, M. et al. In vitro effects of hyaluronic acid on human periodontal ligament cells. BMC Oral Health. 17 (1), 1-12, doi: 10.1186/s12903-017-0341-1 (2017).

19. Babo, P.S. et al. Platelet Lysate-Loaded Photocrosslinkable Hyaluronic Acid Hydrogels for Periodontal Endogenous Regenerative Technology. ACS Biomaterials Science and Engineering. 3 (7), 1359-1369, doi: 10.1021/acsbiomaterials.6b00508 (2017).

20. Graça, M.F.P., Miguel, S.P., Cabral, C.S.D., Correia, I.J. Hyaluronic acid-Based wound dressings: A review. Carbohydrate Polymers. 241 (February), 116364, doi: 10.1016/j.carbpol.2020.116364 (2020).

21. Guo, S.-C., Tao, S.-C., Yin, W.-J., Qi, X., Yuan, T., Zhang, C.-Q. Exosomes derived from platelet-rich plasma promote the re-epithelization of chronic cutaneous wounds via activation of YAP in a diabetic rat model. Theranostics. 7 (1), 81-96, doi: 10.7150/thno.16803 (2017). 
22. Lovisolo, F., Carton, F., Gino, S., Migliario, M., Renò, F. Platelet rich plasma-derived microvesicles increased in vitro wound healing. European Review for Medical and Pharmacological Sciences. 24 (18), 9658-9664, doi: 10.26355/eurrev_202009_23055 (2020).

23. Antich-Rosselló, M., Forteza-Genestra, M.A., Calvo, J., Gayà, A., Monjo, M., Ramis, J.M. Plateletderived extracellular vesicles promote osteoinduction of mesenchymal stromal cells. Bone and Joint Research. 9 (10), 667-674, doi: 10.1302/2046-3758.910.BJR-2020-0111.R2 (2020).

24. Webber, J., Clayton, A. How pure are your vesicles? Journal of Extracellular Vesicles. 2 (1), 1-6, doi: 10.3402/jev.v2i0.19861 (2013).

25. Gómez-Florit, M. et al. Human gingival fibroblasts function is stimulated on machined hydrided titanium zirconium dental implants. Journal of Dentistry. 42 (1), 30-38, doi:

10.1016/j.jdent.2013.11.003 (2014).

26. Théry, C. et al. Minimal information for studies of extracellular vesicles 2018 (MISEV2018): a position statement of the International Society for Extracellular Vesicles and update of the MISEV2014 guidelines. Journal of extracellular vesicles. 7 (1), 1535750, doi: $10.1080 / 20013078.2018 .1535750$ (2018).

\section{Figures}

A

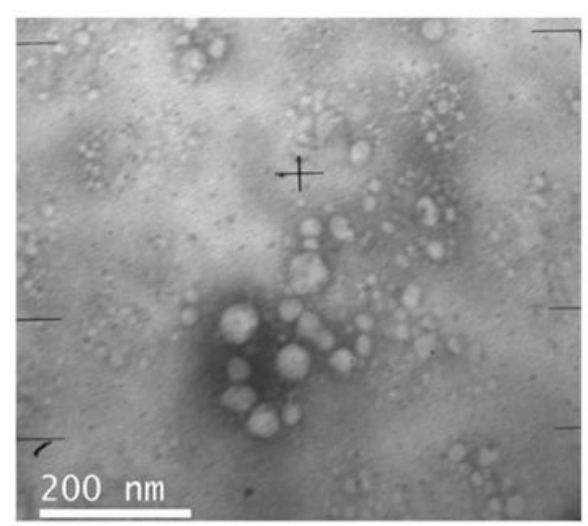

B

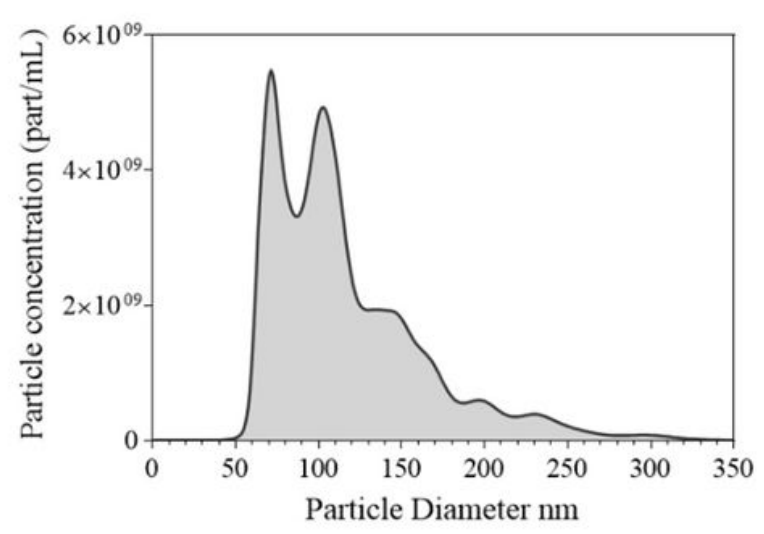

C

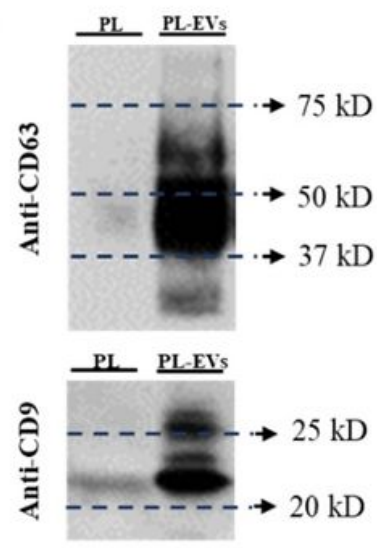

\section{Figure 1}

Platelet-derived extracellular vesicle characterization. (A) Wide-field TEM image of PL-EVs taken at x100k augments. (B) Particle size distribution of EVs determined by NTA analysis (C) Presence of EV biomarkers CD63 and CD9 for PL and PL-EVs. The same amount of protein was loaded per well $(5 \mu \mathrm{g})$. 
A

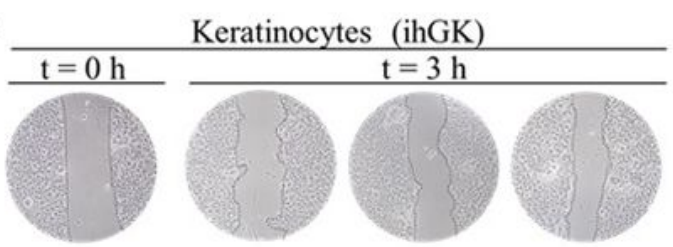

Before

Treatment

B

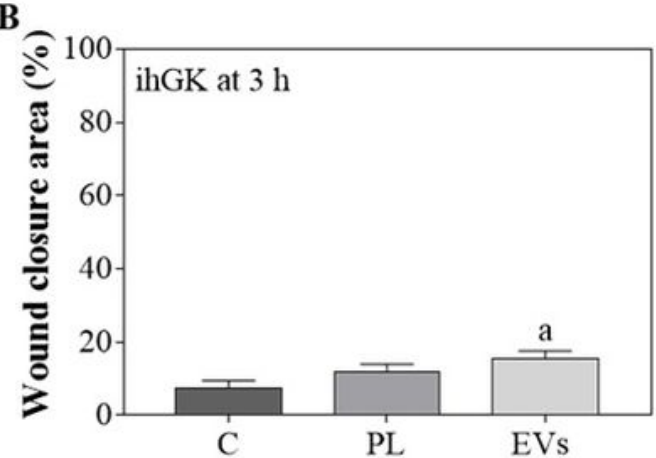

C

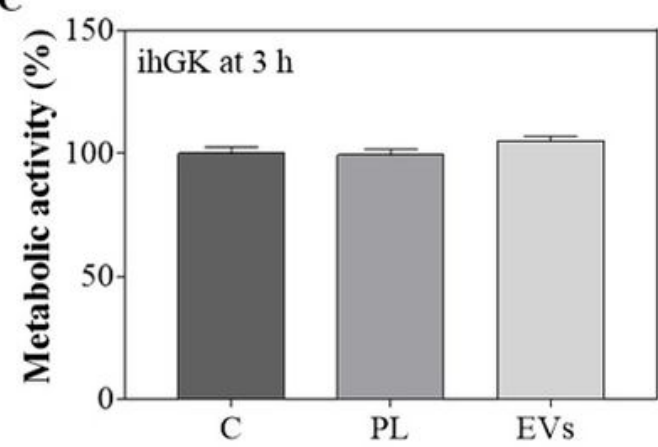

D

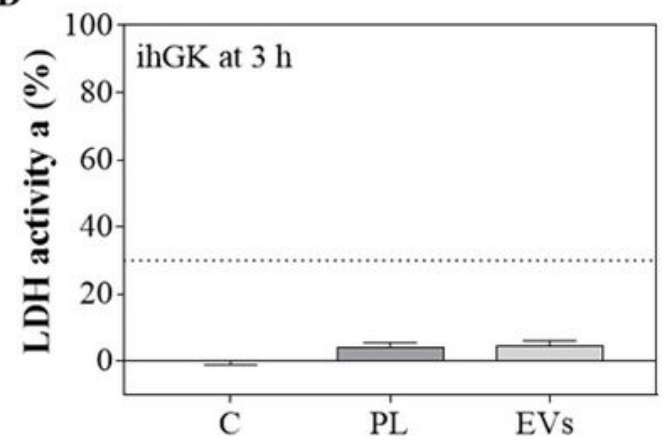

E Fibroblasts (ihGF)

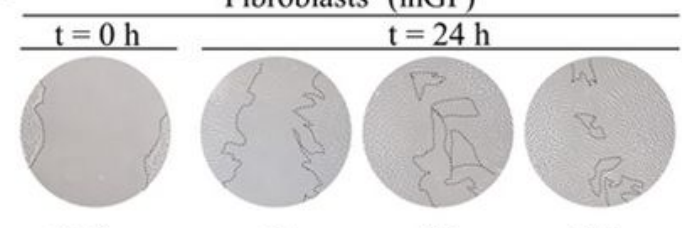

Before

C

PL

EVs

Treatment

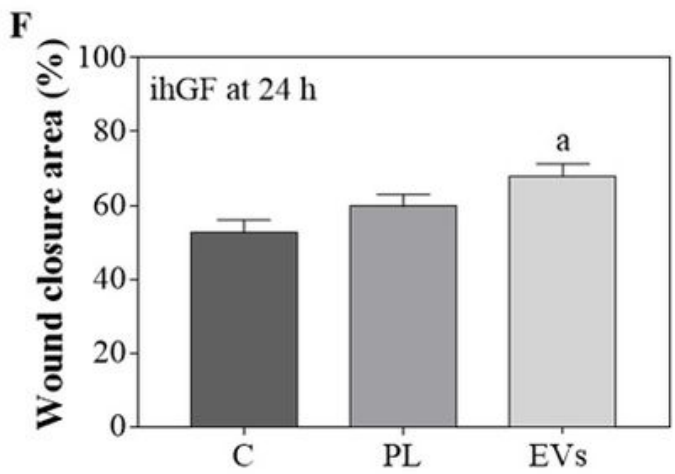

G

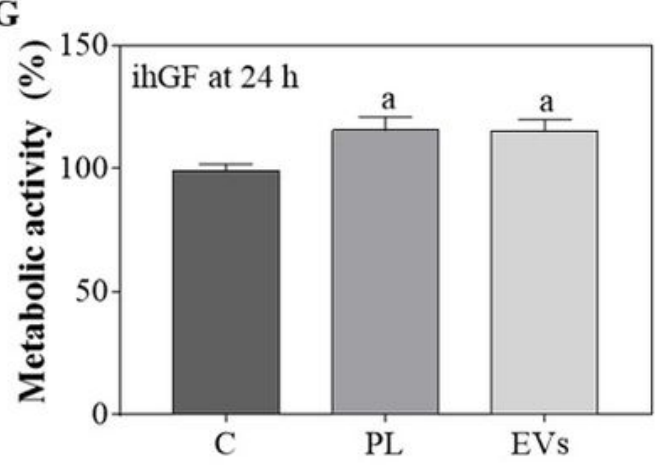

H

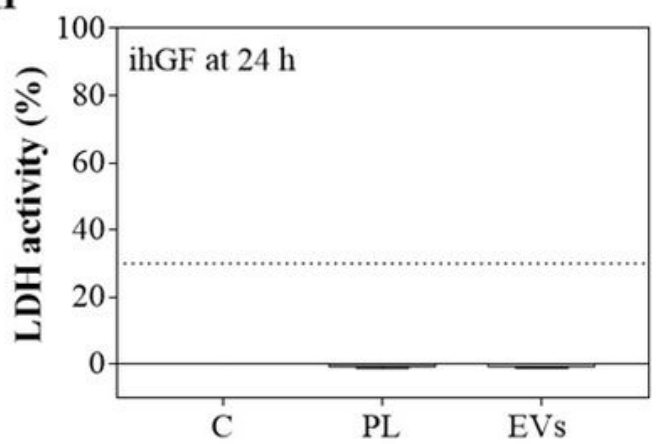

\section{Figure 2}

Effects of PL and EV treatments after the wound healing assay. (A) Images of ihGK cell morphology at $t$ $=0 \mathrm{~h}$ and $\mathrm{t}=3 \mathrm{~h}$ of treatment, images were taken at $\times 100$ augments. (B) Wound closure area after $3 \mathrm{~h}$ of treatment of ihGK. (C) Metabolic activity of ihGK after $3 \mathrm{~h}$ of treatment, data of Control group was set as $100 \%$. (D) LDH activity measured in ihGK culture media after $3 \mathrm{~h}$ of treatment, control group was set as $0 \%$ of toxicity and culture media from cells treated with $1 \%$ Triton X-100 was set at $100 \%$; a dashed line is 
shown at $30 \%$, which is the maximum value accepted for cytotoxicity of medical devices according to ISO-10993:5. (E) Images of ihGF cell morphology at $\mathrm{t}=0 \mathrm{~h}$ and $\mathrm{t}=24 \mathrm{~h}$ of treatment, images were taken at a $\times 100$ augments. (F) Wound closure area after $24 \mathrm{~h}$ of treatment of ihGF. (G) Metabolic activity of ihGF after $24 \mathrm{~h}$ of treatment, data of Control group was set as $100 \%$. (H) LDH activity measured in inGF culture media after $24 \mathrm{~h}$ of treatment, control group was set as $0 \%$ of toxicity and culture media from cells treated with $1 \%$ Triton X-100 was set at $100 \%$.; a dashed line is shown at $30 \%$, which is the maximum value accepted for cytotoxicity of medical devices according to ISO-10993:5. Values represent the mean \pm SEM. Three independent experiments in triplicate $(n=9)$ were performed. Wound closure results were statistically compared by ANOVA using DMS as a post-hoc while metabolic activity results were compared using Mann-Whitney $U$ test. Statistically significant differences were considered for $p<$ 0.05 and represented with a compared to Control. 
A

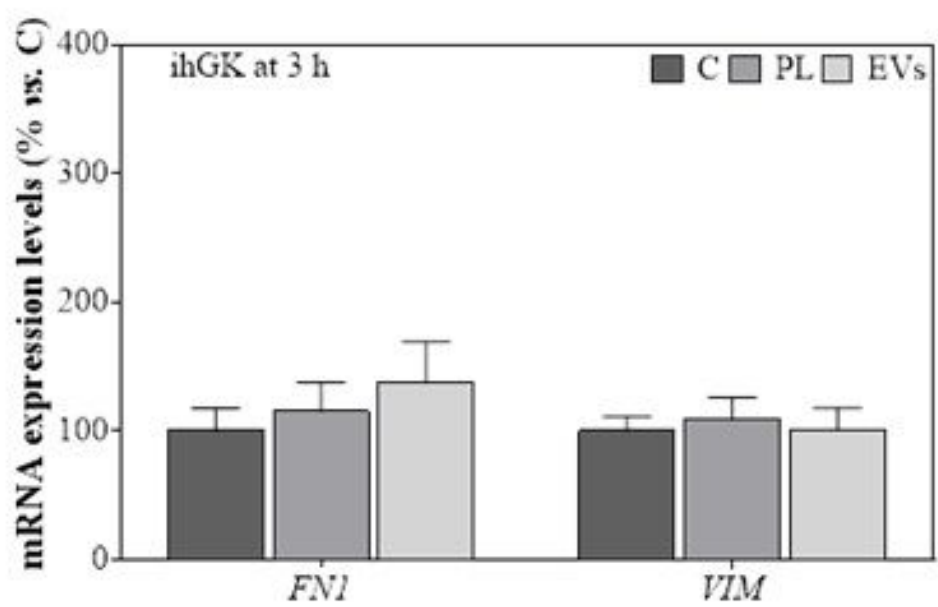

B

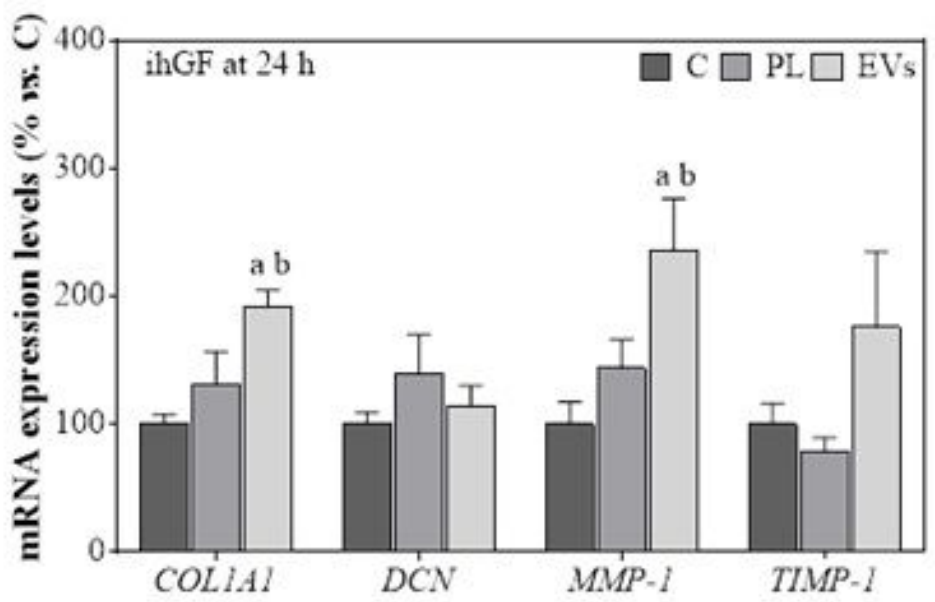

C

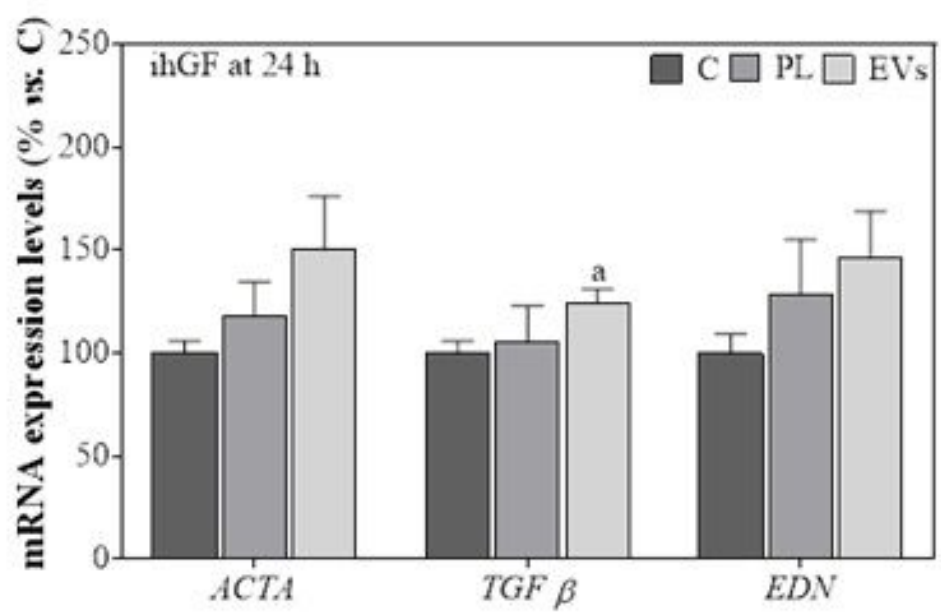

Figure 3

Gene expression levels in ihGK and ihGF after PL and EV treatment. (A) Effects on ihGK mRNA expression levels of FN1 and VIM after $3 \mathrm{~h}$ of treatment. (B) Effects on ihGF mRNA expression levels of COL1A1, DCN, MMP-1 and TIMP-1 after $24 \mathrm{~h}$ of treatment. (C) Effects on ihGF mRNA expression levels of TGF- $\beta 1$, END and ACTA2 after $24 \mathrm{~h}$ of treatment. Values represent the mean \pm SEM. Three independent experiments in triplicate $(n=9)$ were performed. Results were statistically compared by ANOVA and 
Games-Howell for COL1A1 and TGF- $\beta 1$; and by Mann-Whitney U test for MMP-1 and TGF- $\beta$. Statistically significant differences were considered for $p<0.05$ and represented with a compared to $C$ and $b$ compared to PL.
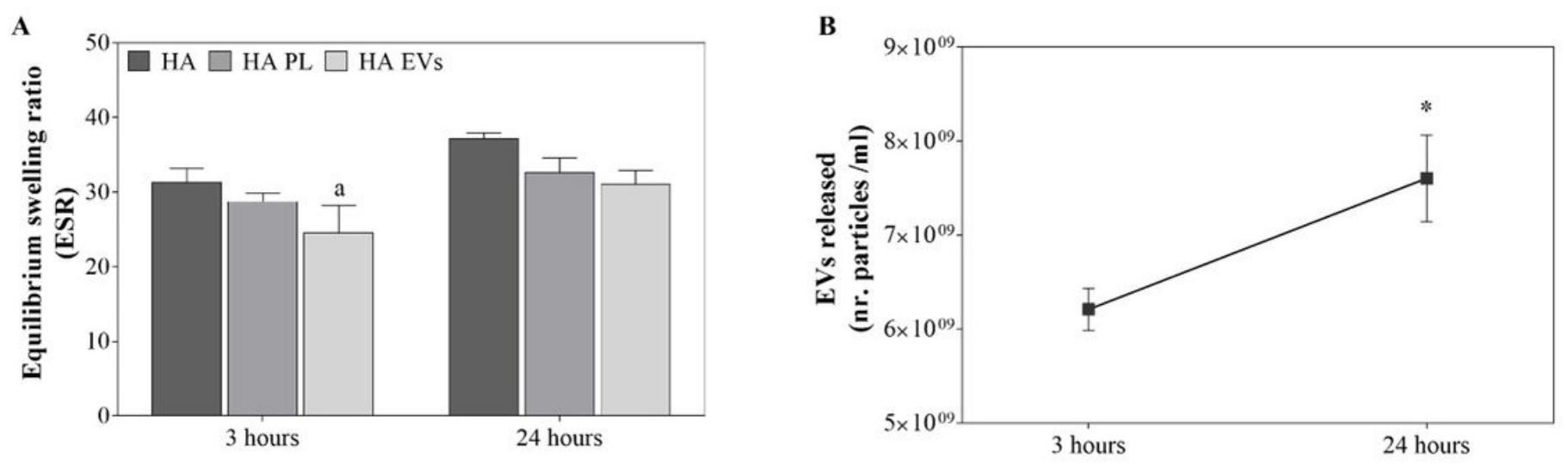

\section{Figure 4}

$\mathrm{HA}$ gels characterization. (A) Equilibrium swelling ratio (ESR) at $3 \mathrm{~h}$ and $24 \mathrm{~h}$ for each gel formulation. (B) EVs released per $\mathrm{mL}$ of HA-EVs gel at $3 \mathrm{~h}$ and $24 \mathrm{~h}$. Values represent the mean $\pm \mathrm{SEM}$. Three independent samples $(n=3)$ were evaluated. ESR results were statistically compared by ANOVA using DMS as a posthoc, while EVs released were compared by independent samples t-test. Statistically significant differences were considered for $p<0.05$ and represented with a compared to HA and * compared to 3 hours. 
A

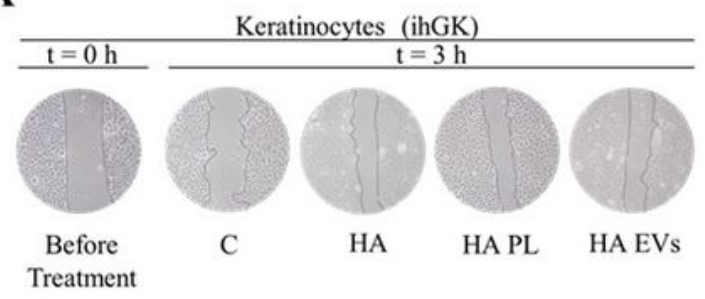

B

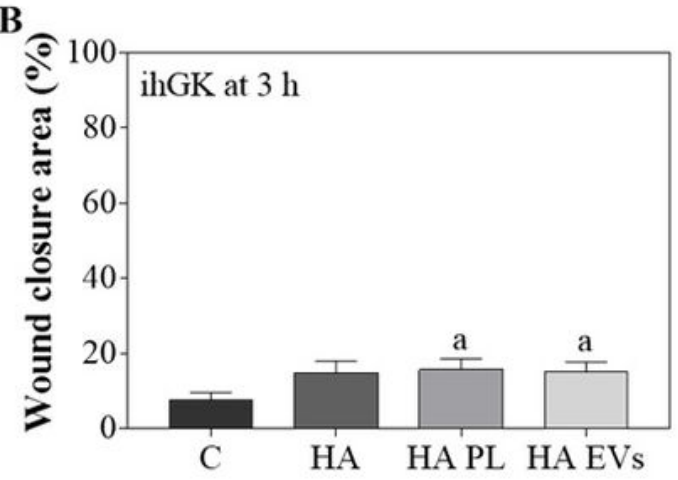

$\mathrm{C}$

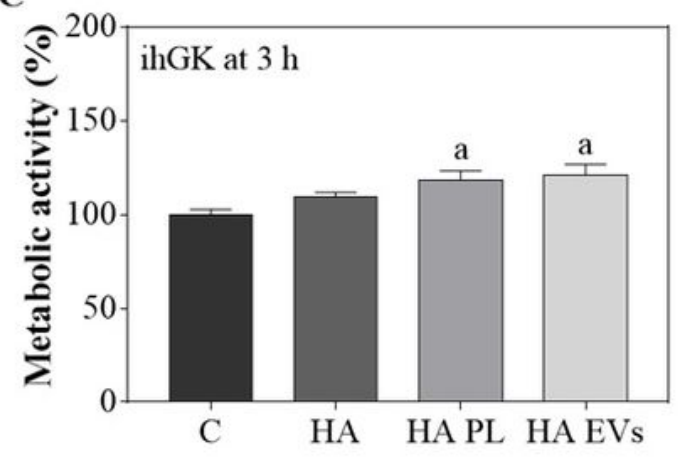

D

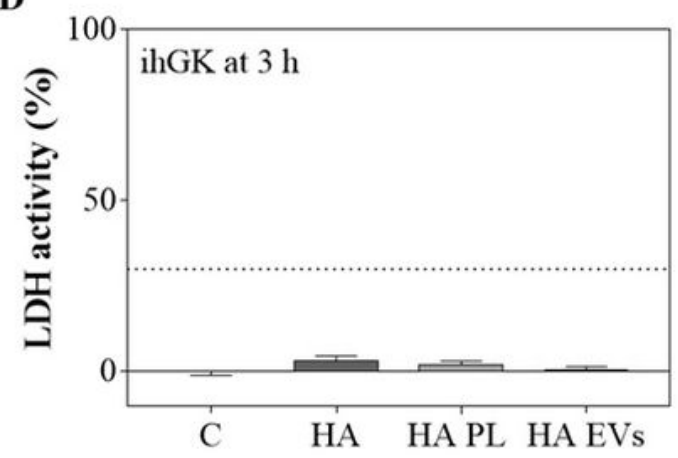

$\mathbf{E}$

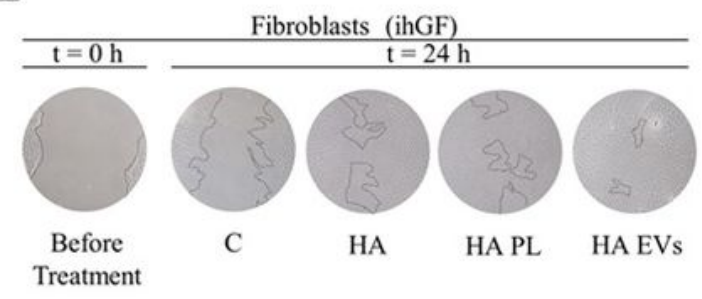

F

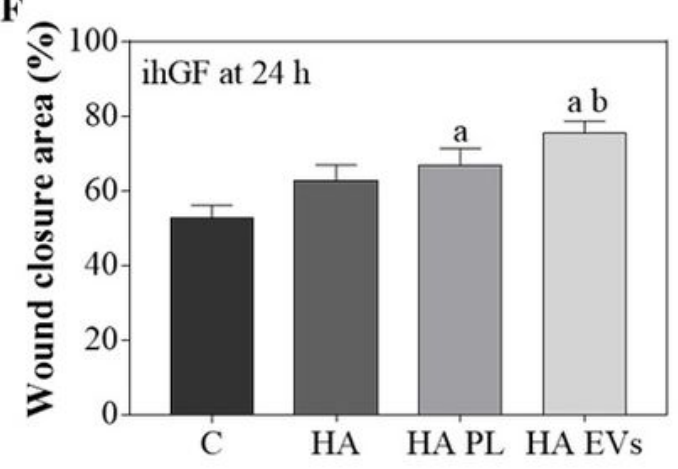

G

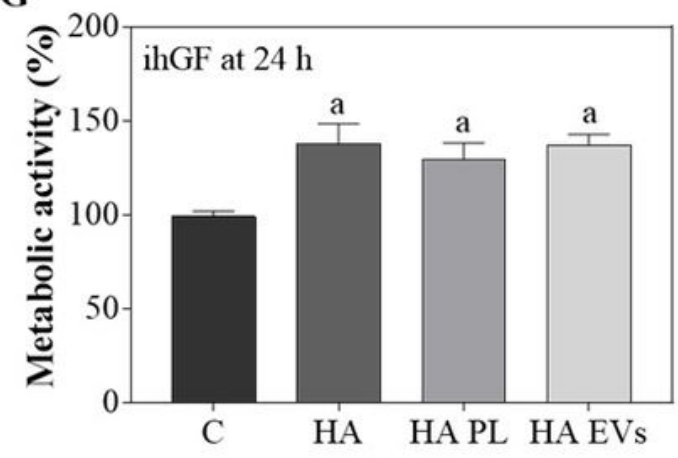

H

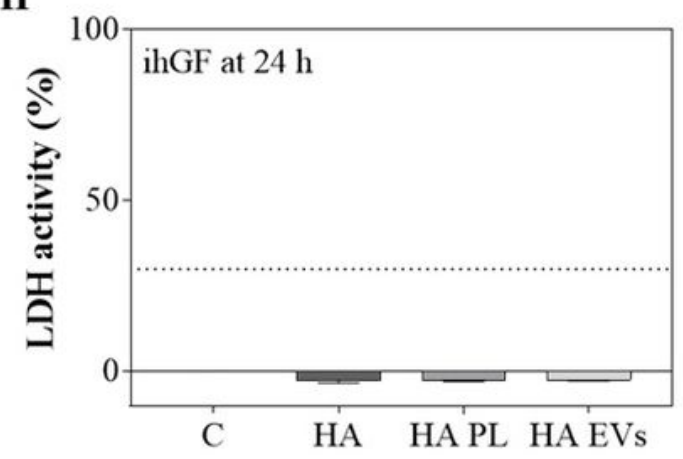

\section{Figure 5}

Effects of HA and its combination with PL and EV after the wound healing assay. (A) Images of inGK cell morphology at $\mathrm{t}=0 \mathrm{~h}$ and $\mathrm{t}=3 \mathrm{~h}$ of treatment, images were taken at $\mathrm{a} \times 100$ augments. (B) Wound closure area after $3 \mathrm{~h}$ of treatment of ihGK. (C) Metabolic activity of ihGK after $3 \mathrm{~h}$ of treatment, data of Control group was set as $100 \%$. (D) LDH activity measured in ihGK culture media after $3 \mathrm{~h}$ of treatment, control group was set as $0 \%$ of toxicity and culture media from cells treated with $1 \%$ Triton X-100 was set 
at $100 \%$; a dashed line is shown at $30 \%$, which is the maximum value accepted for cytotoxicity of medical devices according to ISO-10993:5. (E) Images of ihGF cell morphology at $\mathrm{t}=0 \mathrm{~h}$ and $\mathrm{t}=24 \mathrm{~h}$ of treatment, images were taken at a $\times 100$ augments. $(F)$ Wound closure area after $24 \mathrm{~h}$ of treatment of inGF. (G) Metabolic activity of ihGF after $24 \mathrm{~h}$ of treatment, data of Control group was set as $100 \%$. $(\mathrm{H})$ LDH activity measured in ihGF culture media after $24 \mathrm{~h}$ of treatment, control group was set as $0 \%$ of toxicity and culture media from cells treated with $1 \%$ Triton X-100 was set at $100 \%$; a dashed line is shown at $30 \%$, which is the maximum value accepted for cytotoxicity of medical devices according to ISO-10993:5. Values represent the mean \pm SEM. Three independent experiments in triplicate $(n=9)$ were performed. Wound closure results were statistically compared by ANOVA using DMS as a post-hoc while metabolic activity results were compared using Games-Howell post-hoc. Statistically significant differences were considered for $p<0.05$ and represented with a compared to Control and $b$ compared to HA. 

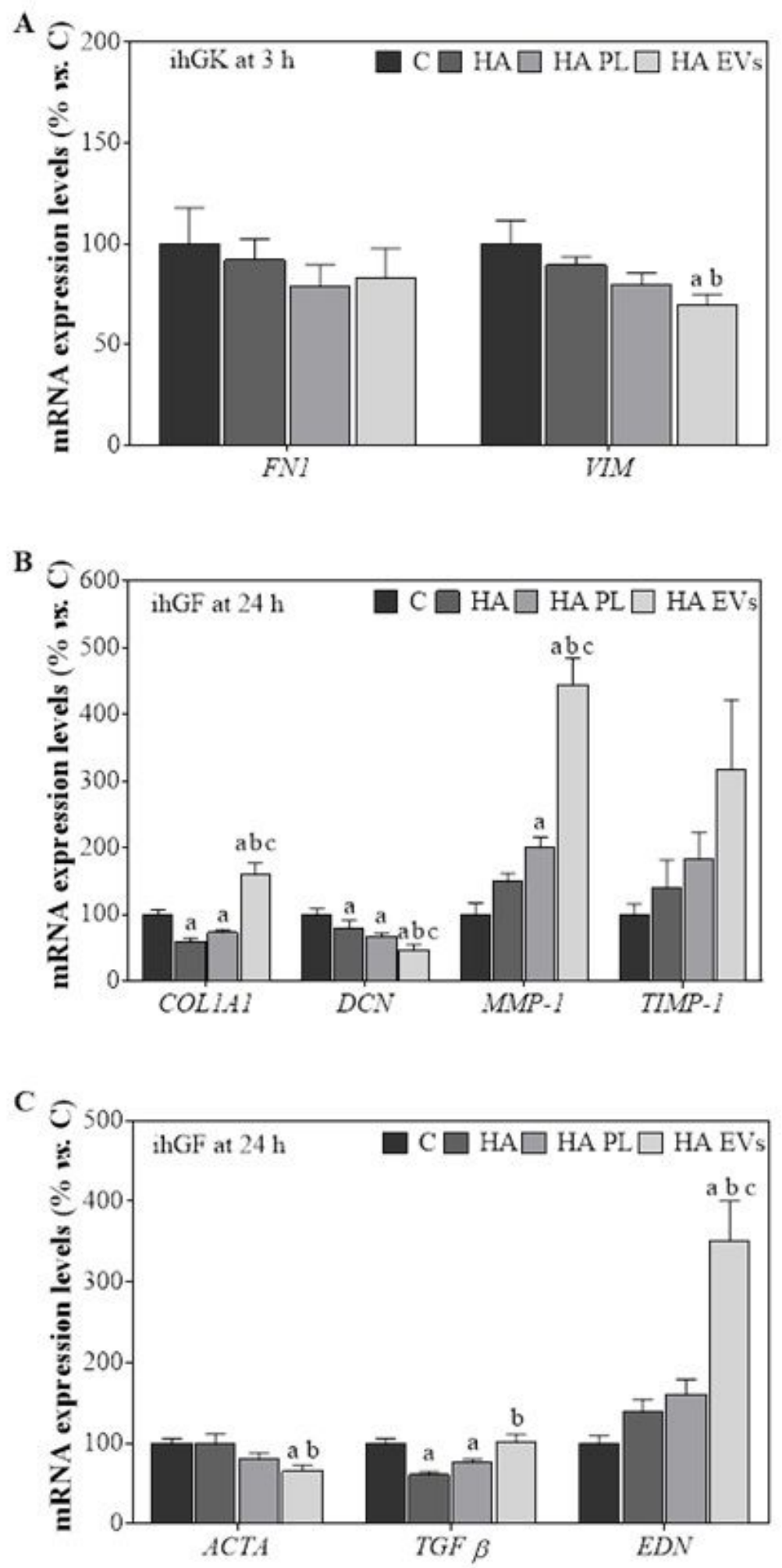

\section{Figure 6}

Gene expression levels in ihGK and ihGF after HA, HA-PL and HA-EV treatment. (A) Effects on ihGK mRNA expression levels of FN1 and VIM after $3 \mathrm{~h}$ of treatment. (B) Effects on ihGF mRNA expression levels of COL1A1, DCN, MMP-1 and TIMP-1 after $24 \mathrm{~h}$ of treatment. (C) Effects on inGF mRNA expression levels of TGF- $\beta 1$, END and ACTA2 after $24 \mathrm{~h}$ of treatment. Values represent the mean \pm SEM. Three independent experiments in triplicate $(n=9)$ were performed. Results were statistically compared by ANOVA and 
Games-Howell for MMP-1, EDN and TGF- $\beta 1$; and by Mann-Whitney $U$ test for COL1A1, DCN and ACTA. Statistically significant differences were considered for $p<0.05$ and represented with a compared to $C$ and b compared to PL. 